LETTER TO EDITOR / CARTA AL EDITOR

\title{
Will our next revolution support or obstruct the achievement of the Sustainable Development Goals?
}

The so-called "Fourth Industrial Revolution" (4IR) ${ }^{1}$, is an emerging phenomenon which will likely transform our lives and affect multiple sectors of society. This new revolution encompasses and combines a wide range of new technologies, such as quantum computing, nano and biotechnology, artificial intelligence (AI), the internet of things (IoT), and advanced automation. Foreseeing all the impacts and ripple effects that these technologies will have in our societies, in the next years, is a sizeable and challenging task. Much of the debate has usually been focused on automation, which the Cambridge Dictionary defines as "the use of machines or computers instead of people to do a job, especially in a factory or office" ${ }^{2}$. The ongoing debate focuses, on the potential of automation to generate production efficiency benefits vs. the threat to increase unemployment lines. However, the actual effects (positive and negative) of this revolution may be much broader and deeper, including social and environmental impacts closely related to sustainable development. Following, we present a brief non-exhaustive commentary on some of the potential advantages and disadvantages of the 4IR from the perspective of the 17 goals adopted by all parties to the United Nations on September 2015, as part of an agenda to tackle global problems and reach sustainable development ${ }^{3}$.

In the United Nations 2030 Agenda $^{3}$, "end poverty in all its forms everywhere" is the first Sustainable Development Goal (SDG 1). In this regard, automation can have a negative effect by creating job losses, particularly in low-income groups, reducing social mobility, and increasing income and wealth inequalities (thus affecting to the SDG 10: "Reduce inequality within and among countries"). This, in a world where there is a gender gap in employment ${ }^{4}$, may disproportionately affect women (thus also hindering the SDG 5: "Achieve gender equality and empower all women and girls"). As Friedrich Soltau explains, the threat to human employment is based on the fast pace of change in production systems which will "displace humans faster that they can adapt, through the acquisition of new skills and education"4. However, a counter argument to all this is that technology development will foster the creation of new businesses, which in turn may bring new and better jobs, thus promoting "sustained, inclusive and sustainable economic growth, full and productive employment and decent work for all" (SDG 8). This, however, clearly depends firstly on whether or not these businesses' socio-environmental impacts also "ensure sustainable consumption and production patterns" (SDG 12), and secondly on their capacity to re-employ those affected, which in itself poses a challenge given that most new jobs will likely require advanced technical knowledge and skills that are not common in low-income populations $s^{5}$. The wide range and growing amount of online educational tools could be part of the solution to this problem. Massive Open Online Courses (MOOC), tutorials, and the vast amount of online freely available information allow people to learn from experts around the world, overcoming the obstacle of physical distance. However, connectivity is a requirement for the spread of online education. That is being addressed by projects such as Amazon Project Kuiper ${ }^{6}$, SpaceX Project Starlink ${ }^{7}$, among others ${ }^{8}$. Thus, automation may help in the goal of ensuring "inclusive and equi- table quality education and promote lifelong learning opportunities for all" (SDG 4). However, going back to jobs, whether these educational tools will help the unemployed to seize opportunities in emerging labor markets will depend on them having access to technology and on having minimal training and knowledge (and, of course, also some spared time). Sadly, this is unlikely to be the case without some government or another kind of support programs, as most of the people whose jobs would be automated do not usually have strong initial education or enough motivation to catch up with the steepest learning curves of emerging jobs such as programming or graphic design?.

Beyond jobs, one of the leading global challenges that humanity is facing, and will increasingly face in the incoming years, is "end hunger, achieve food security and improved nutrition and promote sustainable agriculture" (SDG 2). The use of machines and technology on agriculture has increased food production in the past, hence the belief of some people on the potential benefits of applying aspects of the 4IR on agriculture ${ }^{10}$. One of these benefits could be improving inefficient distribution system and reducing food loss. For instance, software systems are being developed to monitor and analyze data in order to predict the best time to dispatch food production to local markets. Blockchain technology, in turn, offers opportunities to track products along supply chains and validate fair trade schemes ${ }^{11}$. Here, again, the positive impact of these technologies will largely be determined by technology transfer and support for small farmers and applications in remote locations, since "family farms makeup 90 percent of the world's farms and produce over 80 percent of the world's food"12.

"Ensure healthy lives and promote well-being for all at all ages" (SDG 3) may also be influenced by the 4IR. New software applications and technologies using AI seem promising in terms of expanding the reach of medical diagnosis ${ }^{13}$, improving patients' treatments ${ }^{14}$, improving medical records keeping systems ${ }^{15}$, among others. The IoT may also play a role in health, by collecting and analyzing significant amounts of data from different patient scenarios ${ }^{16}$. On the negative side, the IoT's extensive data collection (which goes beyond personal health data) may compromise our privacy ${ }^{17}$ and security ${ }^{18}$. Here too, blockchain technology has been proposed as a way to decentralize information and hinder incorrect practices by central entities ${ }^{19}$; yet, it is clear that having access to such "big data" is in the interest of many groups of individuals whom may not have the health and wellbeing of all in mind.

Since the majority of the human population lives in urban $\operatorname{areas}^{20}$, cities are at the heart of sustainable development. "Making cities and human settlements inclusive, safe, resilient and sustainable" (SDG 11) is yet another personal challenge that the proponents of the 4IR say that it can address ${ }^{21}$ along and aligned with efforts to "build resilient infrastructure, promote inclusive and sustainable industrialization and foster innovation" (SDG 9). Smart city models promise that the application 4IR's technologies, through around-the-clock active sensors, video surveillance cameras, and data collection, will advance good governance and enhance public

'Student at Yachay Tech and Coordinator of the SDSN Andes Youth Network. corresponding author: nicolas.serrano@yachaytech.edu.ec

${ }^{2}$ Lecturer at Yachay Tech and Manager of the SDSN Andes 


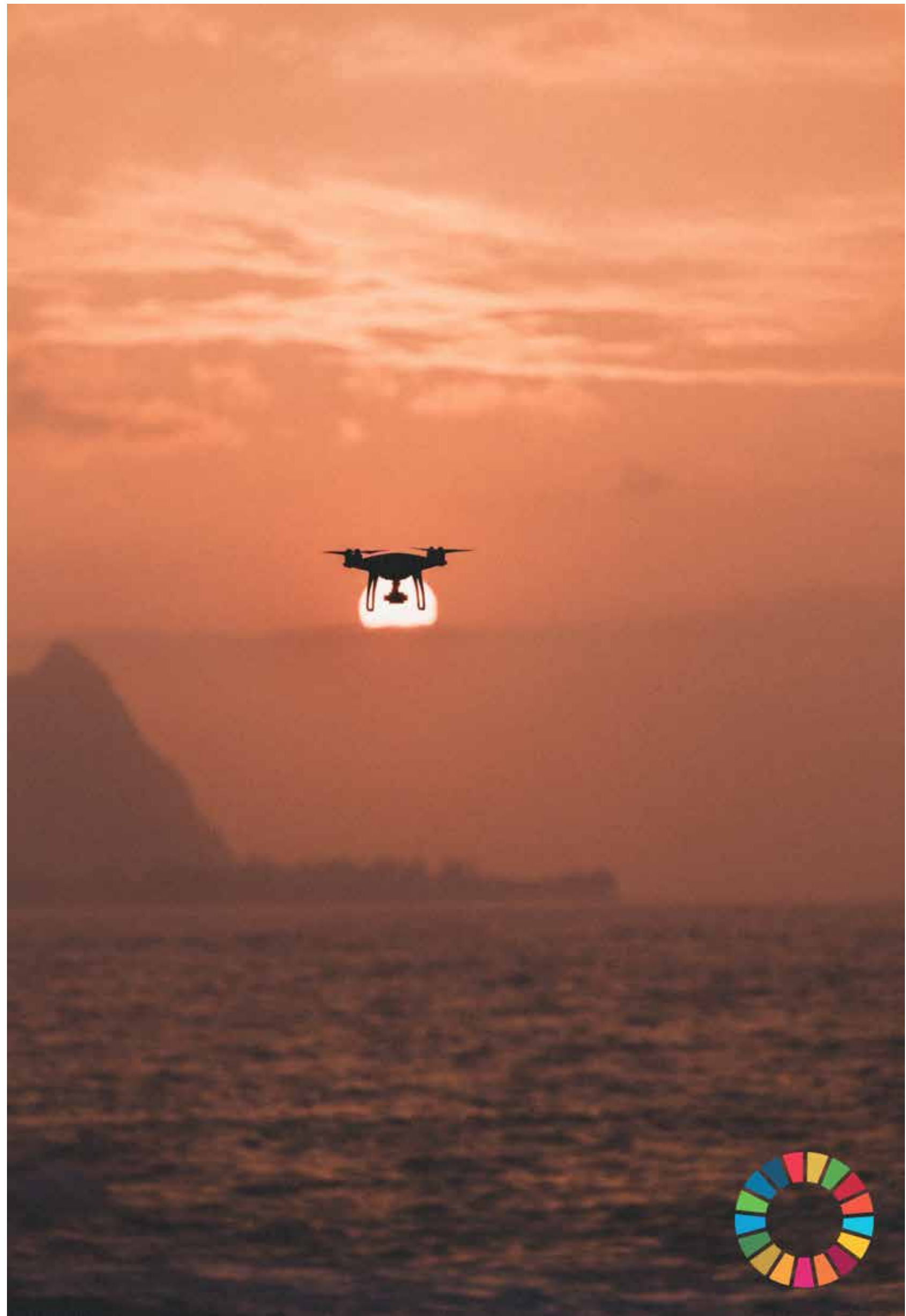


safety $^{22}$. Also, there is the claim that data analysis could address air quality, traffic distribution, electricity supply (thus contributing to SDG 7: "Ensure access to affordable, reliable, sustainable and modern energy for all"), and even water and sanitation (thus also contributing to SDG 6: "Ensure availability and sustainable management of water and sanitation for all") ${ }^{23}$. Here, again, concerns include safety issues. As Kitchin and Dodge ${ }^{24}$ mention, by having everything centralized, we may be more prone to cyber-attacks targeting critical urban systems, such as water supply and electricity grids. In any case, considering that global urban population growth will take place in cities of all sizes, yet the fastest growth will take place in medium-to-small cities mostly located in the global south ${ }^{20}$, if we assume that 4IR's technology will effectively contribute to achieving the aforementioned SDGs, technology transfer will be a significant determining factor.

The need to promote "peaceful and inclusive societies for sustainable development, provide access to justice for all and build effective, accountable and inclusive institutions at all levels" (SDG 16) is another fundamental step towards a better future. Here, more secure, transparent, and efficient software, combined with the automation of some bureaucratic tasks, could bring about more trustable and accountable organizations, for example by reducing human error ${ }^{25}$, and by implementing tamper-evident and less-susceptible-to-modify ledgers that could reduce cases of corruption ${ }^{26}$.

This, of course, is only a brief glimpse of the large number of possible applications and implications of the 4IR. However, are we assessing these opportunities and risks accurately? Alternatively, are we fetishizing technology? ${ }^{27}$. Part of answering these questions is to avoid assuming a cornucopian stance and to acknowledge that all these technologies (alike current technologies) will demand from nature continuous flows of energy and materials, which particularly under our current fossil-fuel-based energy systems and material-extraction practices, will likely imply GHG emissions (thus hindering efforts aimed at achieving SDG 13: "Take urgent action to combat climate change and its impacts") ${ }^{28}$, as well as the further destruction of ecosystems and associated extinction of species ${ }^{29}$. In addition to that, our consumption patterns may quickly transform new products into new waste. The IoT, for instance, maybe causing an "internet of trash" situation where IoT electronic components are disposed after 5 years or less, adding to the problem of e-waste ${ }^{30,31}$, water and soil pollution. All these effects combined, and their ramifications, will in turn hinder our efforts to "conserve and sustainably use the oceans, seas and marine resources for sustainable development" (SDG 14) and to "protect, restore and promote sustainable use of terrestrial ecosystems, sustainably manage forests, combat desertification, and halt and reverse land degradation and halt biodiversity loss" (SDG 15).

Urgently addressing these fundamental questions and challenges is the responsibility of all, at all levels and sectors of society. Besides, effective action requires us to "strengthen the means of implementation and revitalize the Global Partnership for Sustainable Development" (SDG 17). In this line, the Sustainable Development Solutions Network (SDSN), a global initiative working under the auspices of the United Nations Secretary-General, seeks to bring together academia, civil society, public and private sectors in order to work for the achievement of the SDGs ${ }^{32}$. The SDSN has multiple regional and national chapters around the world; among them is the SDSN Andes, currently hosted by Yachay Tech, which seeks to mobilize and connect different sectors of society in order to jointly contribute to the achievement of the SDGs in the Andean Region (Argentina, Bolivia, Colombia, Chile, Ecuador, Peru, and Venezuela).

Will the 4IR be aligned with the sustainable development revolution that we so desperately need? As SDSN Andes, we invite you to think and explore these questions, and ultimately to work on solutions, for your sake and the sake of humanity.

\section{References}

1 Schwab, Klaus. 2017. The fourth industrial revolution.

2 "Cambridge Dictionary," 2019. [Online]. Available: https:// dictionary.cambridge.org/dictionary/english/automation.

3 United Nations General Assembly. Transforming our world: the 2030 Agenda for Sustainable Development. New York, 2015.

4 ILO, "The gender gap in employment: What's holding women back?," 2019. [Online]. Available: https://www.ilo.org/ infostories/en-GB/Stories/Employment/barriers-women\#persistent-barriers.

5 F. Soltau, "Automation and artificial intelligence - what could it mean for sustainable development?," United Nations Dep. Econ. Soc. Aff., pp. 1-4, 2016.

6 Amazon, "Project Kuiper," Low Earth Orbit satellites, 2019. [Online]. Available: https://www.amazon.jobs/en/teams/ projectkuiper.

7 M. Handley, "Delay is Not an Option," pp. 85-91, 2018.

8 UNHCR, “Connectivity for Everyone," 2016.

9 L. Rainie and J. Anderson, "The Future of Jobs and Job Training," no. May, 2017.

10 G. (WEF) Dixie, "The Fourth Industrial Revolution must not leave farming behind," 2018. [Online]. Available: https:// www.weforum.org/agenda/2018/08/the-fourth-industrial-revolution-must-not-leave-farming-behind/.

11 D. Galvin, "IBM and Walmart: Blockchain for Food Safety," $\mathrm{Ibm}, 2017$.

12 FAO. Innovating for our future of food and agriculture. http:// www.fao.org/fao-stories/article/en/c/1170362/.

13 "HealthTap," 2010. [Online]. Available: https://www.healthtap.com/.

14 M. Boaz, K. Hellman, and J. Wainstein, "An Automated Telemedicine System Improves Patient-Reported Well-Being," Diabetes Technol. Ther., vol. 11, no. 3, pp. 181-186, 2009.

15 A. Sunyaev, "Evaluation of Microsoft HealthVault and Google Health personal health records," Health Technol. (Berl)., vol. 3, no. 1, pp. 3-10, 2013.

16 H. J. A. Van Os et al., "The Internet of Things for Health Care: A Comprehensive Survey," Int. J. Stroke, vol. 10, p. $217,2015$.

17 M. Meingast, T. Roosta, and S. Sastry, "Security and Privacy Issues with Healthcare Information Technology."

18 Sadeeq MAM, Zeebaree SRM, Qashi R, Ahmed SH, Jacksi K. Internet of Things Security: A Survey. Int Conf Adv Sci Eng 2018; 88: 162-166. doi:10.1109/ ICOASE.2018.8548785.

19 AIDTech, "Empowering Through Transparency: Transparency As A Service Token (TaaST)," 2018.

20 United Nations, Department of Economic and Social Affairs, Population Division (2014). World Urbanization Prospects: The 2014 Revision, Highlights (ST/ESA/ SER.A/352) 
21 Joshi-Ghani A, Ratti C. A Glimpse into the Future. 2018. https://www.weforum.org/agenda/2018/07/podcast-aglimpse-into-the-future-of-cities-and-urbanization/.

22 B. S. P. Mohanty, U. Choppali, and E. Kougianos, "Everything You Wanted to Know About Smart Cities," no. JULY 2016.

23 Neirotti P, De Marco A, Cagliano AC, Mangano G, Scorrano F. Current trends in smart city initiatives: Some stylised facts. Cities 2014; 38: 25-36. doi:10.1016/j.cities.2013.12.010.

24 R. Kitchin and M. Dodge, "The (In)Security of Smart Cities: Vulnerabilities, Risks, Mitigation, and Prevention," J. Urban Technol., vol. 0, no. 0, pp. 1-19, 2017.

25 D. Landsbergen and G. Wolken, "Realizing the promise : Government information systems and the fourth generation of information technology," Public Adm. Rev., vol. 61 , no. 2, p. 206, 2001.

26 H. Hou, "The application of blockchain technology in E-government in China," 2017 26th Int. Conf. Comput. Commun. Networks, ICCCN 2017, 2017.

27 Hornborg A. Machine fetishism and the consumer's burden. Anthropol Today 2008; 24: 4-5. doi:10.1111/j.14678322.2008.00610.x.

28 C. Mora et al., "Bitcoin emissions alone could push global warming above $2{ }^{\circ} \mathrm{C}$," Nat. Clim. Chang., vol. 8 , no. 11 , pp. 931-933, 2018.

29 Tollefson J. One million species face extinction. Nature. 2019; : 9. http://sci-hub.tw/https://www.nature.com/articles/d41586-019-01448-4\#.

30 United Nations Environmental Management Group, "United Nations System-wide Response to Tackling E-waste," 2017.

31 B. Ellis, "Environmental issues in electronics manufacturing : a review," pp. 17-21, 2000.

32 “SDSN Andes," 2015. [Online]. Available: http://unsdsn.org/ about-us/vision-and-organization/. 